\title{
Flock level seroprevalence of and risk factors for parainfluenza type 3 virus in small ruminants in northern Jordan
}

\section{Waleed Al-Momani*a Mahmoud N. Abo-Shehadab}

aDepartment of Basic Medical Sciences, Faculty of Medicine, Yarmouk University, P.O Box 566 Zip Code 21163, IrbidJordan.

bParasitology Research Laboratory, London School of Hygiene and Tropical Medicine.

Received: $1^{\text {th }}$ Sept 2020 Revised: 20 $^{\text {th }}$ Sept 2020 Accepted: $3^{\text {th }}$ Oct 2020 DOI: https://doi.org/10.31559/CRMI2020.1.1.4

Abstract: Background. Infectious diseases of the respiratory tract of farm animals are caused by a combination of infectious agents and predisposing factors. Parainfluenza virus type 3 is usually nominated as one of the causes. Seroprevalence and animal risk factors for PI3 infections were investigated in northern Jordan. Methods. The study involved 104 small ruminant flocks (18 sheep, 27 goats, and 59 mixed flocks sampled in northern Jordan. Indirect ELISA was used to test 678 blood samples used in this study. Flocks were identified as infected if at least 1 animal has been detected as positive by the ELISA test. Information regarding production and health management practices was collected in a questionnaire. Statistical analysis was conducted using the Statistical Package for Social Sciences software SPSS 23 (SPSS Inc., Chicago, IL, USA). Results. Flock-level and individual-level seroprevalences were 97\%, 37\%, and 76\%, 11\% in sheep and goats respectively. Multivariable logistic regression applied for production and health management practices showed significant risk factors for: Climatic zone $(\mathrm{OR}=0.3)$ was decreasing risk factor for the PI3 seropositivity. Young separated from dams $(\mathrm{OR}=4)$, neonatal deaths $(\mathrm{OR}=3)$, and milking manual $(\mathrm{OR}=37.5)$ were increasing risk factors for the seropositivity of PI3. Conclusions. PI3 virus has a high prevalence in sheep than goats and two risk factors could increase the prevalence of $P I 3$ in both sheep and goats.

Keywords: goat; Jordan; Parainfluenza 3 risk factors; seroprevalence; sheep.

Running title: Risk factors associated with small ruminant PI3 in Iordan.

\footnotetext{
* Corresponding author

Waleed Al Momani

Department of Basic Medical Sciences, Faculty of Medicine, Yarmouk University, Jordan.

E-mail: waleed.momani@yu.edu.jo
} 


\section{Introduction}

Infectious diseases of the respiratory tract of farm animals are caused by a combination of infectious agents and predisposing factors such as inclement weather, the stress of weaning or transportation, and poorly ventilated housing, each of which can weaken the defense mechanism of the animal. Sheep pneumonia is especially common in newborn lambs and feedlot lambs, it can also occur in the mature ewe flocks with milder clinical signs [1]. Pneumonia occurs in all ages of sheep, in all breeds, in every country of the world [2]. As the management practices become more intensive the level and risk of pneumonia become much greater [3]. Close contact allows for the rapid spread of infectious organisms from one lamb to the next. Manure in sheds also leads to the production of ammonia which irritates and damages the respiratory mucosa and reduces the sheep's ability to fight the infection. In shed or semi-confinement lambing operations, pneumonia will peak towards the end of the lambing season in many operations.

Death losses from newborn pneumonia can be as high as $50 \%$ in some flocks. Death is only a part of the actual losses: treatment expense, poor chronic doing lambs, reduced feed efficiency; reduced average daily gains also result from newborn pneumonia infections [2]. Enzootic pneumonia is defined as the common, lowly pathogenic disease of sheep, particularly, lambs, which is common in all sheep populations. Although the disease is well known it is not commonly identified in terms of cause. This is particularly due to its non-fatal character, which leads to an incomplete examination of early cases [4]. Chlamydia, parainfluenza virus type 3 (PI3) virus, adenovirus, a respiratory syncytial virus, reovirus, and mycoplasmas are usually nominated as the cause [5]. The experimental production of a viral $P I 3 / P$. haemolytica pneumonia of lambs demonstrates the preparatory role of the virus, and the resulting highly damaging effects of the Pasteurella) [6]. In Europe and Australia PI3 remains the favored principal cause of undifferentiated pneumonia [7]. In New Zealand antibodies to $P I 3$ and adenovirus are present in lambs soon after birth, but the titer fades so quickly that the lambs become susceptible and infections with the two viruses subsequently spread amongst them [8]. The usual outcome of the experimental infection with $P I 3$ virus is the production of subclinical disease, but there are also reports of clinical illness caused by the virus [9].

Viruses have been isolated from a high proportion of outbreaks of acute illness and also have been related to high levels of pneumonia in slaughtered lambs [10].
Several studies suggest that mainly PI3 and adenoviruses are involved; whereas the roles of other viruses are less clear [11]. Lentiviruses generally induce chronic inflammatory lesion in the lungs and also induce immunodeficiency and consequent susceptibility to opportunistic bacterial, fungal, and viral infections [12,13]. PI3 was first described as causing severe infections of the lower respiratory tract in children and related to many other viruses that have been isolated from different species including sheep [14]. Since PI3 virus has been isolated from sheep in 1966 [14] there have been reports that PI3 infection is widely spread in sheep in many countries $[15,16]$. Antibodies to PI3 are widespread in adult sheep $[17,18]$. It has become increasingly evident that there is a possibility that Pasteurellae are secondary invaders of lungs that have been damaged by viruses such as PI3 [7]. The infection of small ruminants by $P I 3$ causes transient immunodepression [19]. Mild acute respiratory infections are usually due to parainfluenza-3 (PI3) viruses.

There was no seroprevalence study of PI3 in Jordan. This study investigates the seroprevalence of PI3 among sheep and goat flocks in northern Jordan along with some risk factors associated with PI3 seropositivity.

\section{Materials and methods}

Study area and animals. In this study, we followed the methods of Al-Momani et al. 2008 [20]. Small ruminants are the most abundant domestic animals in Jordan, $74.3 \%$ are sheep, and $23.2 \%$ goats [21]. Sheep and goats are usually kept together mainly under free-range roaming transhumance husbandry with a small number of flocks adapting semiintensive husbandry methods [22]. Awassi sheep and local goats are the main small ruminant breeds in Jordan. The routinely recommended control measure for infectious disease is vaccination. Currently, vaccines are used against; enterotoxaemia, brucellosis, Pasteurellosis, Anthrax, pox, foot and mouth disease and pest des petit ruminant, and no vaccine is used against PI3.

Jordan lies at the crossroad of three continents (Asia, Europe, and Africa) and is considered a transit area for animal transportation from the northern to the southern states of the Middle East. There are six climatic zones in Jordan, including, the cool temperate rainy climate, warm temperate rainy climate, cool steppe climate, warm steppe climate, cool desert climate and warm desert climate [23]. Jordan has 4 distinct seasons with an average temperature of $19^{\circ} \mathrm{C}$.

The study area included the five Governorates (Irbid, Mafraq, Zarka, Ajloun and Jerash) of northern Jordan as shown in figure 1. 


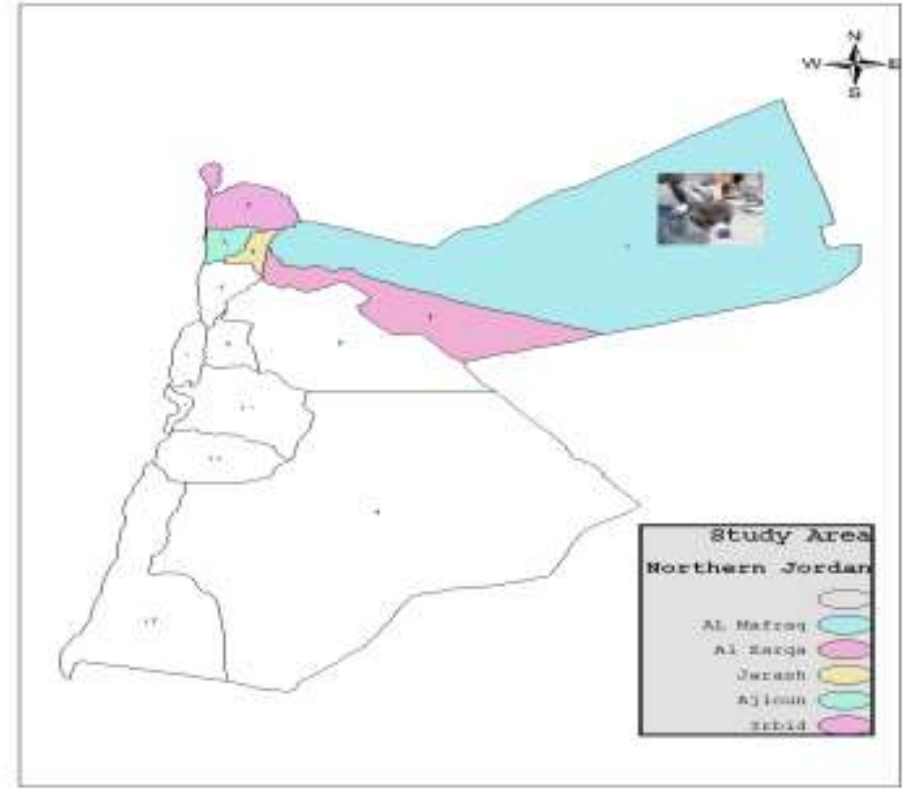

Fig (1): Study area in northern Jordan

The area coordinates are 350 42/-38o 12/ E, $32017 /-32034 / \mathrm{N}$ at 500-1200 m altitude above the sea level and the rainfall varied between 100 and $600 \mathrm{~mm}$. The temperature in winter varies between -4 and $80 \mathrm{C}$ and $29-41^{\circ} \mathrm{C}$ in summer. The main small ruminant farming activities were within 3 climatic zones; the warm desert, cool temperate rainy, and the cool steppe. Flocks practice grazing during spring to early summer and in fall and winter supplements of fodders and concentrates were given. Lambing season lasts from November until May.

Sample size determination and sampling. The prevalence of PI3 infections in northern Jordan was not reported previously, it was assumed to be $50 \%$. The total number of sheep and goat flocks in northern Jordan is estimated to be 10,000 [21]. According to Thrusfield (1995) [24], the appropriate number of flocks to be examined is 62 , because $95 \%$ level of confidence and $5 \%$ absolute precision were required.
The main communal grazing areas were sampled. At least one flock/grazing area was included. Representative flock samples were selected according to the estimated density in each area. The flocks were numbered in each grazing area, and then a number was drawn to be interviewed and sampled. On 7 occasions farmers declined for different reasons; do not like blood to be drawn from their animals, the animal owner was not there to give the permission, absence of adult-male family members, and another number was drawn. Several flocks (39) from the un-shared grazing area (either private or common grazing area with no access to other farmers) were included. Thus, 104 flocks (18 sheep, 27 goats and 59 mixed) having 12093 sheep and 4225 goats were randomly selected. The maximum number of sheep/flock is 620 and the minimum is 20 (Quartiles are $25 \%=40,50 \%=90$, $75 \%=200)$. The maximum number of goat/flock is 300 and the minimum is 8 (Quartiles are $25 \%=15$, $50 \%=25,75 \%=57$ ).

Due to limited funds, the selection of individual sheep/goats for testing included the animal most likely to be infected in the flock (older or poorer condition). Thus, we sampled 5 to 10 animals of $>2$ years of age/flock/species. All single species flocks were sampled, 20 mixed flocks were sampled from both species and 39 mixed-species flocks were sampled from either sheep $(n=24)$ or goat $(n=15)$ depending on the main species in the flock.

Each farm flock was visited once for blood and data collection. Five ml of blood samples were obtained from the jugular veins of each ewe $(n=$ 678) in a vacuum tube without anticoagulant. Serum samples were separated and stored in aliquots at $-20^{\circ} \mathrm{C}$ until used.

\section{Data collection}

A questionnaire was specially designed to collect information using closed questions. The collected information covered production and health management practices (see Table 1). 
Table(1): Description of risk factors for flock-level small ruminant parainfluenza 3 (PI3) seropositivity in northern Jordan

\begin{tabular}{|c|c|c|c|}
\hline \multirow[t]{2}{*}{ Variable } & \multirow[t]{2}{*}{ Coding } & \multicolumn{2}{|c|}{ Seropositivity to $P I 3$} \\
\hline & & No $(n=30)$ & Yes $(n=74)$ \\
\hline \multicolumn{4}{|l|}{ A. Climatic zone ${ }^{b}$} \\
\hline Warm steppe & 0 & 5 & 38 \\
\hline Hot desert & 1 & 8 & 23 \\
\hline Cold temperate & 2 & 17 & 13 \\
\hline \multicolumn{4}{|c|}{ B. Small ruminant species } \\
\hline Sheep & 0 & 3 & 15 \\
\hline Goat & 1 & 14 & 13 \\
\hline Mixed & 2 & 13 & 46 \\
\hline \multicolumn{4}{|c|}{$\begin{array}{l}\text { C. Source of animals, buying } \\
\text { No }\end{array}$} \\
\hline \multirow{2}{*}{ Yes } & 0 & 13 & 32 \\
\hline & 1 & 17 & 42 \\
\hline \multicolumn{4}{|l|}{ D. Drinking water } \\
\hline Rain & 0 & 1 & 1 \\
\hline Spring & 1 & 10 & 34 \\
\hline Pipes & 2 & 4 & 7 \\
\hline Mixed & 3 & 15 & 32 \\
\hline \multicolumn{4}{|c|}{ E1. Grazing localitya } \\
\hline Same village & 0 & 26 & 53 \\
\hline Local area & 1 & 4 & 17 \\
\hline Others & 2 & 0 & 4 \\
\hline \multicolumn{4}{|c|}{ E2. Communal grazing } \\
\hline No & 0 & 17 & 22 \\
\hline Yes & 1 & 13 & 52 \\
\hline \multicolumn{4}{|c|}{ E3. Grazing and concentrate } \\
\hline No & 0 & 10 & 24 \\
\hline Yes & 1 & 20 & 50 \\
\hline \multicolumn{4}{|c|}{ F1. Introduce SR into farm } \\
\hline No & 0 & 19 & 45 \\
\hline Yes & 1 & 11 & 29 \\
\hline \multicolumn{4}{|c|}{ F2. Use outsider rams } \\
\hline No & 0 & 25 & 49 \\
\hline Yes & 1 & 5 & 25 \\
\hline \multicolumn{4}{|c|}{ F3. Sources of breeding animals* } \\
\hline Local area & 0 & 19 & 59 \\
\hline Other & 1 & 1 & 3 \\
\hline & 2 & 10 & 12 \\
\hline G1. Young separ & & & \\
\hline $\begin{array}{l}\text { No } \\
\text { Yes }\end{array}$ & 0 & 19 & 21 \\
\hline & 1 & 11 & 53 \\
\hline G2. Newborn ba & & & \\
\hline Yes & 0 & 17 & 36 \\
\hline & 1 & 13 & 38 \\
\hline H1. Weaning ag & & & \\
\hline No & & & \\
\hline Yes & 0 & 26 & 63 \\
\hline & 1 & 4 & 11 \\
\hline H2. 2-6 months & & & \\
\hline No & 0 & 5 & 14 \\
\hline Yes & 1 & 25 & 60 \\
\hline I1. Udder cleani & & & \\
\hline No & 0 & 14 & 56 \\
\hline Yes & 1 & 16 & 18 \\
\hline I2. Change in mi & & & \\
\hline No & & & \\
\hline Yes & 0 & 25 & 50 \\
\hline & 1 & 5 & 24 \\
\hline I3. Milking man & & & \\
\hline No & 0 & 4 & 1 \\
\hline Yes & 1 & 26 & 73 \\
\hline $\begin{array}{l}\text { I4. Cleaning mill } \\
\text { No }\end{array}$ & & & \\
\hline Yes & 0 & 19 & 48 \\
\hline & 1 & 11 & 26 \\
\hline J1. Neonatal dea & & & \\
\hline No & 0 & 20 & 30 \\
\hline Yes & 1 & 10 & 44 \\
\hline
\end{tabular}


Table(1) (Continued)

\begin{tabular}{|c|c|c|c|}
\hline \multirow[t]{2}{*}{ Variable } & \multirow[t]{2}{*}{ Coding } & \multicolumn{2}{|c|}{ Seropositivity to $P I 3$} \\
\hline & & No $(n=30)$ & Yes $(n=74)$ \\
\hline \multicolumn{4}{|c|}{ J2. Neonatal death/year } \\
\hline No death & 0 & 14 & 25 \\
\hline$<5$ & 1 & 8 & 24 \\
\hline $5-10$ & 2 & 5 & 15 \\
\hline$>10$ & 3 & 3 & 10 \\
\hline \multicolumn{4}{|c|}{ K1. Parasitic infection } \\
\hline Absent & 0 & 14 & 30 \\
\hline Present & 1 & 16 & 44 \\
\hline \multicolumn{4}{|c|}{ K2. Treat against parasite } \\
\hline No & 0 & 13 & 15 \\
\hline Yes & 1 & 17 & 59 \\
\hline \multicolumn{4}{|c|}{ K3. When signs appear } \\
\hline No & 0 & 17 & 39 \\
\hline Yes & 1 & 13 & 35 \\
\hline \multicolumn{4}{|c|}{ K4. Respiratory signs } \\
\hline Absent & 0 & 12 & 27 \\
\hline Present & 1 & 18 & 47 \\
\hline \multicolumn{4}{|c|}{ K5. Mastitis } \\
\hline Absent & 0 & 12 & 20 \\
\hline Present & 1 & 18 & 54 \\
\hline \multicolumn{4}{|c|}{ K6. Abortion } \\
\hline No & 0 & 19 & 31 \\
\hline Yes & 1 & 11 & 43 \\
\hline \multicolumn{4}{|c|}{ K7. Loss of weight } \\
\hline No & 0 & 24 & 57 \\
\hline Yes & 1 & 6 & 17 \\
\hline \multicolumn{4}{|c|}{ L1. Veterinary supervision } \\
\hline No & 0 & 14 & 57 \\
\hline Yes & 1 & 16 & 17 \\
\hline \multicolumn{4}{|c|}{ L2. Trust vet } \\
\hline No & 0 & 1 & 12 \\
\hline Yes & 1 & 29 & 62 \\
\hline \multicolumn{4}{|c|}{ M1. Vaccines used } \\
\hline No & 0 & 17 & 30 \\
\hline Yes & 1 & 13 & 44 \\
\hline \multicolumn{4}{|c|}{ M2. Pasteurella } \\
\hline Yes & 0 & 28 & 68 \\
\hline No & 1 & 2 & 6 \\
\hline \multicolumn{4}{|l|}{ M3. PPR } \\
\hline Yes & 0 & 26 & 54 \\
\hline No & 1 & 4 & 20 \\
\hline
\end{tabular}

a Significant $p<0.25$, ${ }^{\mathrm{b}}$ Significant $p<0.05$

The questionnaire was filled by direct interviews with the farmers and conducted by a veterinarian who spoke the same dialect of Arabic as the farmers, so there wasn't any problem in communication.

Detection of PI3 by ELISA. To detect the antibodies of PI3 in the sera of sheep and goats indirect ELISA has been used [25]. The ELISA kits were supplied by (BIOX diagnostics, Belgique). $100 \mu \mathrm{l} /$ well of the serum (1/100 dilution) has been added to all the 96 wells. The plates were incubated at $37^{\circ} \mathrm{C}$ for 1 hour and then washed 3 times with the washing buffer. Then $100 \mu \mathrm{l}$ of anti-bovine immunoglobulinperoxidase conjugate (horseradish peroxidaselabeled anti-bovine IgG1 monoclonal antibody) diluted 1/ 50 was added to each well and incubated at $37 \mathrm{oC}$ for 1 hour; then the wells were washed 3 times with the washing buffer. $100 \mu \mathrm{l} /$ well of a freshly prepared chromogen-substrate (Tetramethylbenzidine) mixture was applied to all the 96 wells. The plates were incubated for 10 minutes at room temperature protected from light. The color development was stopped by $50 \mu$ of a stopping solution. The absorbance was determined at $450 \mathrm{~nm}$ by BIO-TEK INSTRUMENTS, ELX 800 ELISA plate reader.

To interpret the results, the value recorded for the even column (negative control) was subtracted from the odd column. The signal read for each sample well was divided by the corresponding positive control serum signal and the result was multiplied by 100 to express it as a percentage. The degree of positivity of serum was determined using the quality control procedure table; a result greater than or equal to one plus sign $(+)$ was considered as positive.

Statistical methods. The seroprevalence [26] and 95\% confidence intervals were calculated for seroprevalence. Chi-square analysis was employed to test the significance of prevalences. $P$-value of $<$ 0.05 was considered significant. The odds ratio and its 95\% confidence intervals were calculated. Statistical analysis was performed by using the Statistical Package for Social Sciences software SPSS 23 (SPSS Inc., Chicago, IL, USA).

Data were analyzed according to the case-control design, where PI3 seropositive and seronegative flocks were compared to the exposure to potential risk factors [24]. Variables that were associated with 
PI3 seropositive flocks at $\mathrm{p}<0.25$, were used in multivariable logistic regression [27]. It was checked whether these variables showed a correlation of more than 0.05 with each other.

In the multivariable model, variables were excluded from the model by the forward procedure. The least-significant variables (based on Wald's statistic) were deleted, the model fitted and the results then compared (both parameters estimate and the difference in -2log likelihood of the model) with those of the previous run to check for confounding with a change in parameter estimates of more than $30 \%$, the deleted variable was considered to be a confounder and included in the model again. This resulted in a model containing variables related to PI3 seropositivity ( $p<0.05$ ). Two-way interaction was tested for significance.

\section{Results}

Seroprevalences of PI3 were calculated and analyzed as; (1) flock-level seroprevalence for small ruminants (both sheep and goats); sheep and goats (2) individual-level seroprevalence for small ruminant (sheep and goats), sheep and goat (Table 2).

Table(2): Seroprevalence of seropositivity to PI3 in small ruminant flocks by iELISA in northern Jordan

\begin{tabular}{|c|c|c|c|c|}
\hline \multirow{2}{*}{ Species } & \multicolumn{2}{|c|}{ Flock-level } & \multicolumn{2}{|c|}{ Individual-level } \\
\hline & $\begin{array}{c}\text { No. } \\
\text { examined }\end{array}$ & Prevalence & $\begin{array}{c}\text { No. } \\
\text { examined }\end{array}$ & Prevalence \\
\hline Small ruminant & 104 & $74(71 \%)$ & 678 & $317(45 \%)$ \\
\hline Sheep & 62 & $60(97 \%)$ & 376 & $286(76 \%)$ \\
\hline Goat & 62 & $23(37 \%)$ & 302 & $33(11 \%)$ \\
\hline
\end{tabular}

The seroprevalences of $P I 3$ were $97 \%, 37 \%$ in small ruminants (sheep and goats) respectively. There was a high significant $(\mathrm{X} 2=47, \mathrm{P}=0.00001$, OR $=51,95 \%$ CI: 11,156$)$ difference between the flock level seroprevalences of sheep and goats. At the individual-level the seroprevalences of $P I 3$ were $76 \%$ and $11 \%$ in sheep and goat respectively, there was also a highly significant difference between sheep and goats $(\mathrm{X} 2=279, \mathrm{P}=0.00001, \mathrm{OR}=26$, 95\% CI: 16, 37).

Multivariable analysis

Out of 32 variables 7 variables were associated $(\mathrm{P}<0.25)$ with PI3 seropositivity. After forward selection (Table 3 ).

Table(3): Distribution of titration level of Parainfluenza 3 in small ruminants

\begin{tabular}{lcccccc}
\hline Grading & 0 & 1 & 2 & 3 & 4 & 5 \\
Sheep & & & & & & \\
No. & 90 & 117 & 86 & 54 & 18 & 14 \\
& 24 & 31 & 23 & 14 & 4 & 4 \\
Goat & & & & & & \\
No. & 269 & 28 & 5 & 0 & 0 & 0 \\
& 89 & 9 & 2 & 0 & 0 & 0 \\
\hline
\end{tabular}

only four variables remained in the final logistic regression model, namely; climatic zone, young separated from dams, neonatal deaths and milking manual (Table 4).

Table(4): Logistic regression analysis of factors associated with seropositivity to parainfluenza type 3 virus in small

\begin{tabular}{llll}
\multicolumn{4}{c}{ ruminants flocks in northern Jordan } \\
\hline Risk factor & $P$ & OR & $95 \% \mathrm{CI}$ \\
& & & \\
\hline Cold Climatic zone & 0.001 & 0.3 & $0.2-0.6$ \\
Young separated from dam & 0.015 & 4.00 & $1.4-12$ \\
Neonatal death & 0.032 & 3 & $1.0-9.0$ \\
Milking manual & 0.005 & 37.5 & $3,5-10$ \\
\hline
\end{tabular}

\section{Discussion}

Respiratory infections are the major causes of pneumonia among small ruminants in Jordan $[28,29]$ which has an economic impact on the small ruminant industry in Jordan. Respiratory diseases may be caused by a variety of infective agents in conjunction with genetic, environmental, management, and nutritional factors [3]. Indirect ELISA is considered as an acceptable test to investigate the prevalence of antibodies $P I 3$ in sera of the studied animals [25]. This is the first study in Jordan to associate production and health management practices with the seroprevalence of PI3 antibodies in sheep and goats.

Table 2 and Table 3 show the seroprevalence and titration level in sheep and goat at a flock and individual level. Our results showed that the majority (97\%) of Jordanian sheep flocks was seropositive for PI3 antibodies and the seroprevalence of goat flocks was 37\%. The individual seroprevalence of $P I 3$ in sheep was $76 \%$ with a titration level of $(++)$ in $45 \%$ of the positive animals while the individual seroprevalence of goats was $11 \%$ with a titration level of $(++)$ in $2 \%$ of the positive animals. There was a highly significant $(\mathrm{P}=$ $0.00001, \mathrm{OR}=51$ ) difference between the flock level seroprevalence of sheep and goats. At the individual-level the seroprevalences of PI3 were $76 \%$ and $11 \%$ in sheep and goats respectively, there was also a highly significant difference at the individual level between sheep and goats $(\mathrm{P}=$ $0.00001, \mathrm{OR}=26)$. This indicates that sheep are more susceptible to PI3 infections than goats.

This result is not surprising where $P I 3$ is considered to be one of the most common viruses in sheep; PI3 has been isolated from the respiratory 
tract of sheep in the united states [30]; 87.2\% of the lambs had antibodies to $P I 3$ at a ram lamb station in the united states [26]. $82 \%$ of sheep in Peru were seropositive for PI3 antibodies [31]. In the Middle East, $P I 3$ was one of the prevalent viruses in Syria with $24 \%$ of samples were positive [32].

In a previous study, total of 31 variables including production and health management practices were tested as risk factors for seropositive flocks for $M$. agalactiae and analyzed using logistic regression analysis. Increasing risk factors for $M$. agalactiae seropositive flocks were: using outsider rams, improper cleaning of the milking utensils and separating young from the dam, with odds ratios of $5,3,4.2$, respectively; having mastitis problems in the flock was negatively associated $(P=0.04)$ with $M$. agalactiae seropositivity. Educating small ruminant farmers to avoid the use of outsider rams, ensuring adequate cleaning of milking utensils and separating the young from dams would enhance the health of small ruminants [20].

These analyses allowed us to identify several risk factors associated with seroprevalence of PI3. In this study, out of 32 health management and production variables only four, namely, climatic zone, young separated from dams, neonatal deaths and milking manual were found as risk factors for PI3 seropositivity.

Climatic zone (Cold climate) $(\mathrm{OR}=0.3,95 \% \mathrm{CI}$ : $0.15,0.6)$ was a decreasing risk factor for $P I 3$ seropositivity. The studied area which includes 3 different climatic zone had a considerable effect on PI3 seropositivity; as we moved toward the high mountain in western Jordan which is only a small area, the seroprevalence of PI3 was decreasing, this may be due to the big change in temperature in other parts of the studied area, the use of mountain caves at night in the cold zones and may also be due to the dusty airborne in the warm steppe and hot desert areas which is a major cause of spreading the infection among animals.

Contrary to expectations, keeping the young separated from the dam $(\mathrm{OR}=4,95 \% \mathrm{CI}: 1.4,12)$ was an increasing risk factor leading to increasing seropositivity in animals in the flock. This may be due to a lack of maternal immunity transferred to the young animal through the colostrum which can protect them from infections. Also, milk produced from ewes separated from lambs and kids is pooled and some of it is used for feeding the young. Pooling milk will ensure that the organism secreted in milk (of the infected animal(s)) will reach the maximum number of animals in the flock.

Neonatal death $(\mathrm{OR}=3 ; 95 \% \mathrm{CI}: 1,9)$ had a positive correlation with PI3 seropositivity, indicating that the presence of PI3 in these flocks may lead to increase neonatal death problem in these flocks.
The traditional way of milking the animals (Milking manual) $(\mathrm{OR}=37.5 ; 95 \% \mathrm{CI}: 3,510)$ by keeping the animals very close and face to face could facilitate the transmission of PI3 from the infected animals to healthy ones. Direct contact and aerosol transmission may be an important route in transmitting PI3.

\section{Conclusions}

$P I 3$ virus has a high prevalence in sheep than goats and 3 risk factors, young separated from dams, neonatal deaths and milking manual could increase the prevalence of PI3 in both sheep and goats while climatic zone was decreasing risk factor. PI3 is an important cause of respiratory tract infections in small ruminants and associated with production and health management practices in sheep and goats in Jordan.

Data Availability: The data used to support the findings of this study are included in the article.

Conflict of interest: The authors declare that there is no conflict of interest regarding the publication of this manuscript

\section{References}

[1] Jared, D. Taylor, J. D. Robert W. Fulton, R. F. Terry W. Lehenbauer, T. W. L. Douglas L. Step, D. L. \& Anthony W. Confer, A. W. (2010). The epidemiology of bovine respiratory disease: What is the evidence for predisposing factors? Canadian Veterinary Journal. 51(10): 1095-1102.

[2] Chakraborty, S. Kumar, A. Tiwari, R,. Rahal, A. Malik, Y. Dhama, K. Pal, A. \& Prasad, M. (2014). Advances in Diagnosis of Respiratory Diseases of Small Ruminants, Vet Med Int; 2014:1-6, https://doi.org/10.1155/2014/508304.

[3] Marru, H. D. Anijajo, T. T. \& Hassen, A. A. (2013). A study on ovine pneumonic pasteurellosis: isolation and identification of Pasteurellae and their antibiogram susceptibility pattern in Haramaya District, Eastern Hararghe, Ethiopia, BMC Veterinary Research. 9(1):239, https://doi.org/10.1186/1746-6148-9-239.

[4] Mark, L. D. \& Weiser, G. C. (2017). Potential disease agents in domestic goats and relevance to bighorn sheep (Ovis canadensis) management, PLOS ONE, 12(3): e0173396, https://doi.org/10.1371/journal.pone.0173396.

[5] Franco, M. F. Gaeta, N. C. Alemán, M. A. R. Priscilla A. Mellville, P. A. Jorge Timenetsky, J. Mário F.A. Balaro, M. F. A. Gregory, L. (2019). Bacteria isolated from the lower respiratory tract of sheep and their relationship to clinical signs of sheep respiratory disease. Brazilian Journal of veterinary research. 39 .

[6] Mohamad, R. A. \& Abdelsalam, E. B. (2008). A review of pneumonic pasteurellosis (respiratory manheimosis) with emphasis on pathogenesis, virulence mechanism and predisposing factors. Bulgarian Journal of Veterinary Medicine, 11(3): 139-160.

[7] Stevenson, R. G. (1969). Immunoflourescence studies of parainfluenza 3 virus in the lungs of lambs, Journal of Comparative Pathology , 79(4): 483-488, https://doi.org/10.1016/0021-9975(69)90068-1. 
[8] Davies, D. H., Davies, G. B. and Price, M. C. (1980). A longitudinal serological survey of respiratory virus infections in lambs, New Zealand Veterinary Journal, 28(7):

125-127, https://doi.org/10.1080/00480169.1980.34721.

[9] Wang, H. Y. Tong, Q. Wang, W. Wu, H. (2014). Serological survey of antibodies against bovine parainfluenza virus type 3 in 12 provinces. Zhongguo Yufang Shouyi Xuebao / Chinese Journal of Preventive Veterinary Medicine. 36(2): 154-156.

[10] Lyon, M., Leroux, C., Greenland, T., Chastang, J., Patet, J. \& Mornex, J. F. (1997). Presence of a unique parainfleunza virus 3 strain identified by RT-PCR in visna-maedi virus infected sheep, Veterinary Microbiology , 57(3): 95-104, https://doi.org/10.1016/s0378-1135(97)00104-1.

[11] Martin, W. B. (1983). Respiratory disease induced in small ruminants by viruses and mycoplasma, Revue Scientific et Technique, Office International des Epizooties 2(2): 311-378, https://doi.org/10.20506/rst.2.2.116.

[12] Haas, A. P. (1986). Pathogenesis of lentivirus infections, Nature, 322(6075): 130-136, https://doi.org/10.1038/322130a0.

[13] Narayan, O. \& Clements, J. E. (1989). Biology and pathogenesis of lentiviruses. Journal of GeneralVirology, 70(7): 1617-1639, https://doi.org/10.1099/0022-1317-70-7-1617.

[14] Ljubiša Veljović, L. Knežević A. Nenad Milić, N. Krnjaić, D. Miković, R. et al. (2016). Isolation and Molecular Detection of Bovine Parainfluenza Virus Type 3 in Cattle in Serbia, Acta Veterinaria, 66(4): 4, 509-519, https://doi.org/10.1515/acve-2016-0044.

[15] Adair, B. M., McFerran, J. B., McKillop, E. R. \& McCullough, S. J. (1984). Survey for antibodies to respiratory viruses in two groups of sheep in Northern Ireland, Veterinary Record, 115(16): 403406, https://doi.org/10.1136/vr.115.16.403.

[16] Paul, M., Akoua-Koffi, C., Buchwald, N., Schubert, G., Weiss, S., Couacy-Hymann, E., Anoh,A. E., Mossoun, A., Calvignac-Spencer, S., Leendertz, S. A., Leendertz, F. H. \& Ehlers, B. (2015). Adenovirus in Rural Côte D'Ivoire: High Diversity and Cross-Species Detection, EcoHealth, $12 \quad$ (3):441-452, https://doi.org/10.1007/s10393-015-1032-5

[17] Brako, E. E., Fulton, R. W. \& Nicholson, S. S. (1984). Prevalence of bovine herpesvirus-1, bovine viral diarrhea, parainfluenza 3 , goat respiratory syncycial, bovine leukemia and bluetongue viral antibodies in sheep, American Journal of Veterinary Research 45: 813-816,

[18] Keshaw, T., Sean, H. M., Kelsey, M., Carol, P., Claude, D., Derek, T. \& Ravindra, N. S. (2016). Seroprevalence of Antibodies to Bovine Herpes Virus Type-1 (BoHV1 ) in Ruminants of Grenada, West Indies Journal of Animal Research: 6(6): 939-942, https://doi.org/10.5958/2277-940x.2016.00134.0

[19] Kenedy,-Stokopf, S., Narayan, O. \& Hirsh, L. R. (1983). Immunosuppression in goats inoculated with parainfluenza type 3 virus, American Journal of Veterinary Research, 44: 2302-2306,

[20] Al-Momani W., Nicholas, R. A. J. and Abo-Shehada, M. N. (2008). Risk factors associated with Mycoplasma agalactiae infection of small ruminants in northern Jordan, Preventive Veterinary Medicine, 83 (1): 110, https://doi.org/10.1016/j.prevetmed.2007.08.003.

[21] Anonymous, (2016). The Annual Report, Ministry of Agriculture, Jordan,

[22] Abo-Shehada, M. N. (1997). Management of the National Sheep and Goat Flock Health in Jordan. The proceeding of the Conference of Management Development in The Agriculture Sector in Arab Countries, Bradford, England. 24-26,

[23] Anonymous, (1984). National Atlas of JordanClimate and Agroclimatology, Jordan National Geographic Center. pp. 135

[24] Thrusfield, M. (1995). Veterinary Epidemiology, Blackwell Science, London, p. 182, 1995.

[25] Riedemann, S., Montecinos, M. I, \& Tadich, N. (1991). Serological survey for antibodies in parainfleunza 3 virus in sheep in Chile, Veterinary Record, 128(24): 572, https://doi.org/10.1136/vr.128.24.572.

[26] Rogan, W. J. \& Gladen, B. (1987). Estimating prevalence from the results of a screening, American Journal of Epidemiolog, 107(1):71-76, https://doi.org/10.1093/oxfordjournals.aje.a112510.

[27] Hosmer, D. \& Lemeshow, S. (1989). Applied logistic regression, Wiley, New York, pp.307.

[28] Abo-Shehad. M. N., Arab, B., Mukbel, R., Williams ,D. \& Torgerson, P. R. (2002). Age and seasonal variations in the prevalence of Oestrus ovis larvae among sheep in northern Jordan, Preventive Veterinary Medicine, 47(3): 205-212, https://doi.org/10.1016/s01675877(00)00160-4.

[29] Al-Momani, W., Halablab, M. A., Abo-Shehada, M. N., Miles, K., McAuliffe, L. \& Nicholas, R. A. J. (2006). Isolation and molecular identification of small ruminant mycoplasmas in Jordan, Small Ruminant Research, 65(1-2): 106-112. https://doi.org/10.1016/j.smallrumres.2005.05.022.

[30] Lehmkuhl, H. D. \& Cutlip, R. C. (1982). Charactrization of parainfluenza type 3 virus isolated from the lung of a lamb with pneumonia, American Journal of Veterinary Research, 43: 626-628,

[31] Lehmkuhl, H. D., Cutlip, R. C., Bolin, S. R. \& Brogden, K. A. (1985). Seroepidemiological survey of antibodies to selected viruses in the respiratory tract of lambs, Journal of Veterinary Research, 46: 26012604,

[32] Giangaspero, M., Vanopdenbosch, E., Nishikawa, H. \& Tabbaa, D. (1997). Prevalence of antibodies against respiratory viruses (parainfluenza virus type 3, respiratory syncytial virus, reovirus and adenivirus) in relation to productivity in Syria Awassi sheep, Tropical Animal Health and Production, 29(2): 8391, https://doi.org/10.1007/bf02632323. 